\title{
Challenges in Energy and Innovation Competence Construction Practices in China
}

\author{
CHEN Wu \\ State Grid Energy Research Institute, \\ Beijing, China \\ hurricane5186@163.com
}

\author{
CHANG Yan \\ School of business, Central University \\ of Finance and Economics, Beijing, \\ China ; State Grid Energy Research \\ Institute, Beijing, China \\ emily_chang@126.com
}

\author{
ZHAO Gang \\ Economics\& Management School of \\ Wuhan University, Wuhan, \\ China; Electric Power of \\ HeNan, Zhengzhou, China \\ 31375883@qq.com
}

\begin{abstract}
With the increasing tension of fossil energy resources and the development of new energy utilization, the world is undergoing profound changes in energy. Based on the analysis of the world energy trends, this paper gives a thorough expounded analysis on China's energy situation and challenges comprehensively, then it researches the requirements and challenges that the energy technological change has brought to power grid technology. Finally, it introduces the successful practice of scientific and technological innovation capability building of the central enterprises coping with the energy changes with the example of SGCC, and how does State Grid Corporation of China (SGCC) prepare for energy technological changes. It aims at providing reference for other companies of China to construct scientific innovation system.
\end{abstract}

Key Words-Energy Technological Changes, Science and Technology Innovation Capability, Electric Power Grid Enterprise, State Grid Corporation of China (SGCC)

\section{INTRODUCTION}

With the increasing tension of fossil energy resources, new energy development has become the world's energy security and sustainable development focus areas. In the era of energy continuous changes, electric power has become the core of the future final energy consumption gradually, and the functions and roles of grid are therefore becoming significant changes. In order to meet the energy technology revolution and the development of new energy sources, grid technology is experiencing unprecedented challenges. Grid companies must adapt to changes in energy technology, and promote technological change and upgrade the grid technology. In this background, it is essential for the power grid enterprises to build science and technology innovation capability actively, to enhance the ability to prepare for the technology changes. SGCC has built a sound science and technology innovation system; try to enhance the science and technology innovation capability to meet the challenges of the energy revolution on the basis of holding the world energy development trend and the world grid development trend accurately.

\section{THE WORLD ENERGY DEVELOPMENT TRENDS}

World energy development has gone through four stages: firewood era (before the end of the 19th century), the coal era (from the end of the 19th century to the 1960s), the oil era (from 1960s to about 2025), the electricity era of carrying clean energy and energy effective use (it will begin a gradual transition after the 2020s). We hold that the world energy will transform to the electricity era of carrying clean energy and energy effective use gradually.

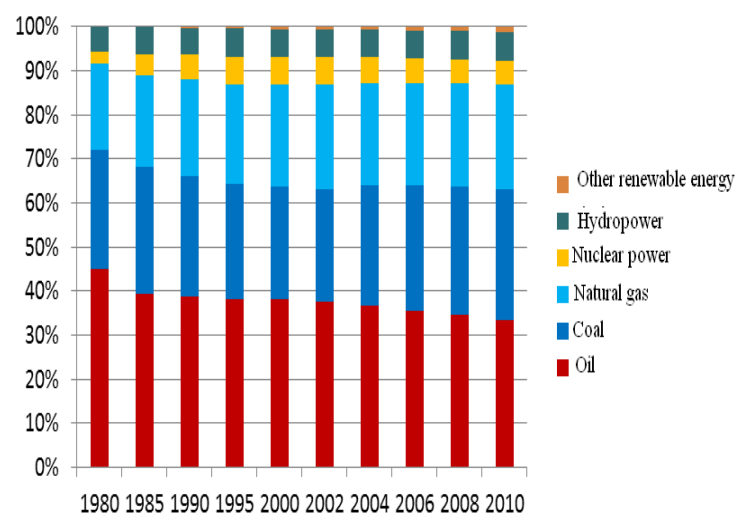

Fig. 1 World Primary Energy Consumption Structures Changes

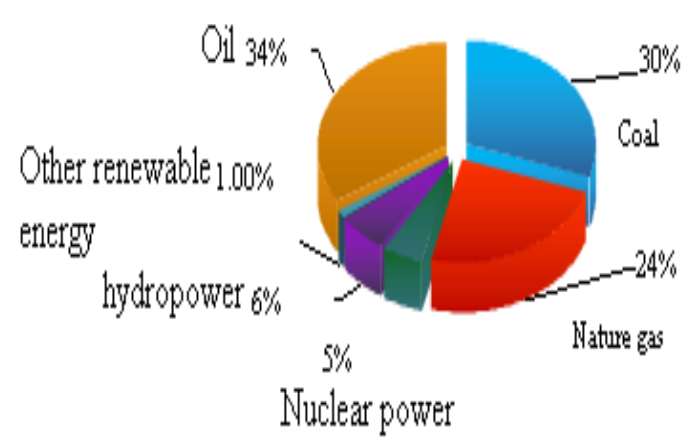

Fig. 2 World Primary Energy Consumption Structures in 2010

According to the BP World Energy Statistics, the world primary energy consumption trends are as follows: (1) the proportion of oil in primary energy consumption declined gradually; the share of coal decreased and then showed an upward trend; oil and coal remains the dominant fuel. In 2010, the proportion of oil and coal accounted for the total global 
consumption of $33.6 \%$ and $29.6 \%$. (2) The proportion of natural gas increased gradually, basically stable at $23.4 \%$. (3) The proportion of hydropower, nuclear power and other renewable energy increased gradually, reaching at $13 \%$. The changes are shown in Figure 1, 2.

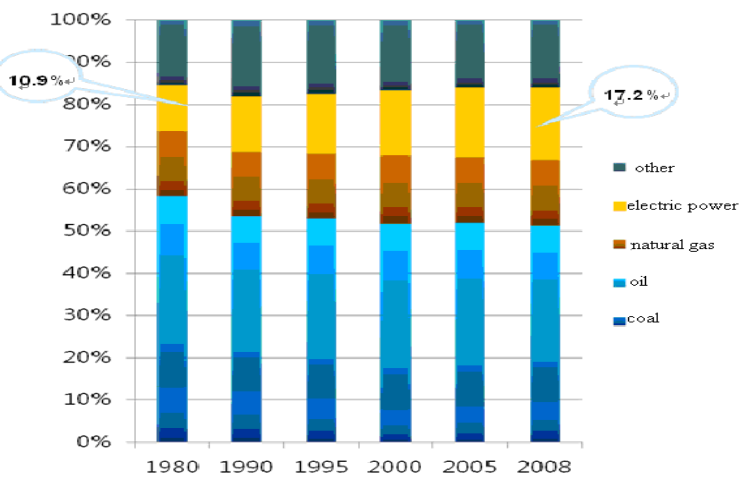

Fig. 3 World Final Energy Consumption Structure Changes

According to the International Energy Agency (IEA) data, the trends of the world final energy consumption are showed as following: (1) the consumption proportion of fossil energy continued to decline; (2) the proportion of coal are less than $10 \%$ over the past decade; (3) With more fossil fuels being transformed into electricity consumption, the proportion of electricity in final energy consumption is continuing to increase, reaching at $17.2 \%$, and it showed rapid growth trend in the 21 century. The changes are shown in Figure 3.

Looking at the world's energy consumption trends, the world energy revolution has shown the following main features: (1) World Energy will maintain a longer period of time that the basic pattern of fossil energy-based (at least maintain this status to the middle of this century); (2) Energy security has rise to an important component of national security (especially oil supply); (3) the diversification of world energy, clean technology, and effective development, the worldwide deployment of energy resources will gradually increase the size (as the important part of globalization.)

\section{The SituATION AND CHALLENGES OF ENERGY DEVELOPMENT IN CHINA}

The situation and challenges of energy development in China are shown in Figure 4.

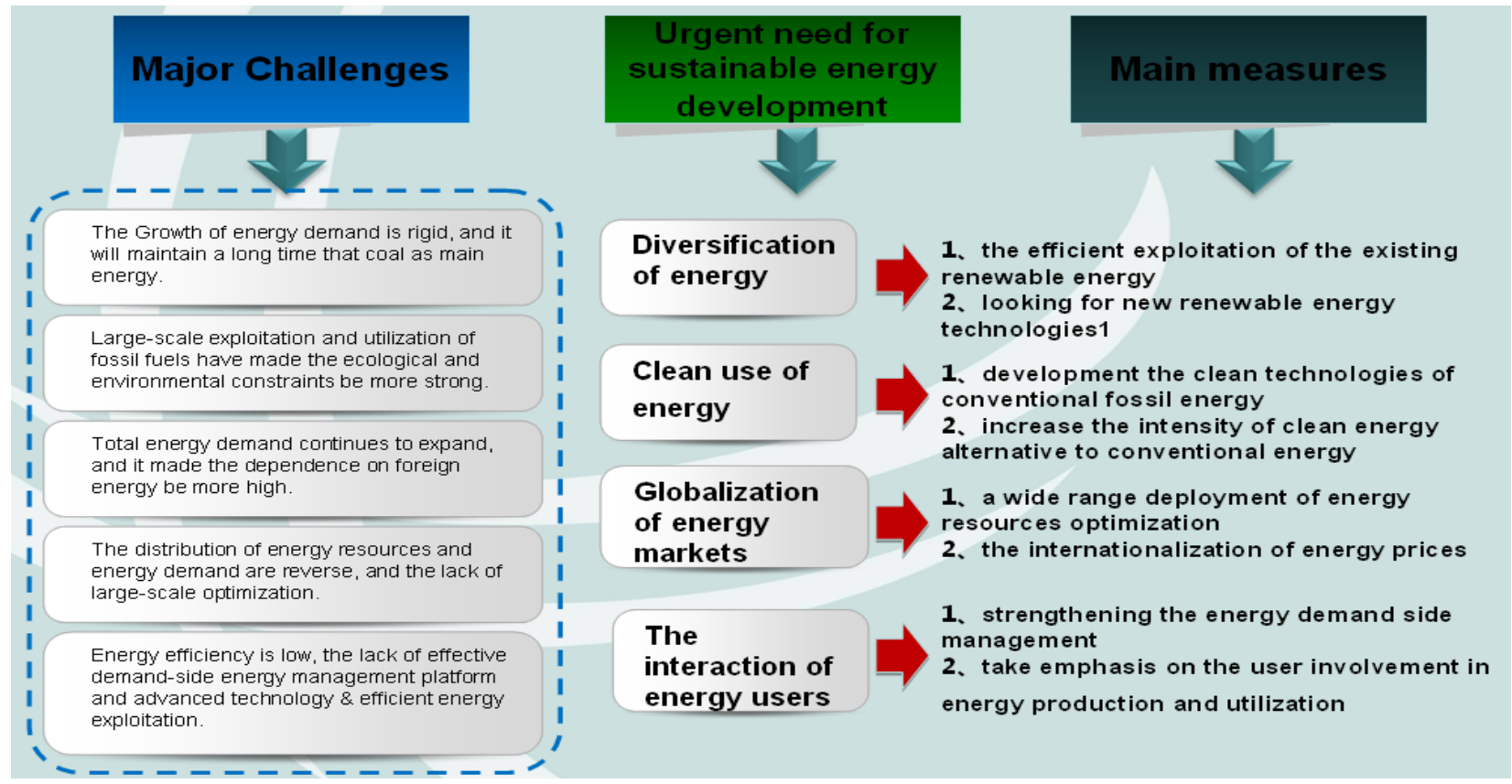

Fig. 4 The Situation and Challenges of Energy Development in China

Facing this grim situation and challenges, the role of the grid is undergoing major changes; and the grid is becoming a hub for energy use and platform. Grid is an important hub for clean energy exploitation and utilization, and it will play an important role in the development of low-carbon economy as a support infrastructure and important platform to promote low-carbon economy. Its functions are as follows: (1) It will provide a platform for clean energy exploitation, transportation, and utilization, and it also will promote energy supply system become low-carbon system; (2) It will provide a support platform for the government to put low-carbon economy policy into practice; (3) It will promote national energy transporting system optimization and cost-effective operation; (4) It will promote the efficient use of final energy consumption, and lead to the transformation of electricity using concepts, and make consumption mode be adapt to low-carbon economy.

\section{ENERGY TRANSFORMATION AND GRID TECHNOLOGY TRENDS IN CHINA}

The energy changes require a major shift in the function of grid, and it has brought five major challenges for the grid 
technology in China:

(1) To improve the grid's ability of optimizing the allocation of energy resources in a wide range continuously. $76 \%$ of China's coal resources located in the north and northwest, $80 \%$ of the water resources located in the southwest, the land wind energy is concentrated in the "Three North" (northwest, north, northeast) region, but more than $70 \%$ of the energy demand is concentrated in the east. This status of energy resources distribution requires us to implement large-scale (250 million $\mathrm{kW}$ ), long-distance (more than $1000 \sim 3000 \mathrm{~km})$, more economical, safer, more environment friendly electric power delivery. Therefore, the challenges of grid technologies are as follows: to master large-scale, long-distance, high-efficiency power transmission technology and equipment manufacturing capability; to construct a strong power grid which is adapted to many types of large-scale energy-consumptive coordination at all levels; to establish effective co-operation multi-level power trading system.

(2) To upgrade the grid's capability of accepting renewable energy continuously. By 2020, China's plan: 7 million kilowatts wind power base, the wind power scale will reach 150 million kwh; 20000 rooftop photovoltaic projects, the scale will reach one million kwh; Golden Sun projects will reach 5 million projects; large number of million kilowatts of light $\mathrm{V}$ base, the scale will reach 20 million kwh. The new energy development make the grid must meet the technical, economic requirements. The challenges of grid are as follows: intermittent and peaking changes increase the pressure of grid, and will influence the normal operation of hydro and thermal power plants; the poor control and anti-disturbance ability, and the poor support ability for stability will worsen the power system stability sometimes; high voltage and long distance transmission is technical difficulties of large-scale exploitation which must be resolved. Therefore, The challenges of grid technologies are as follows: to master the operation characteristics of clean energy; to master the technologies of operation, control and security and defense of large-scale intermittent energy; to master the technologies that grid accepts a wide range distributed power; to research the advanced energy storage system which can stabilize the fluctuations of the electric power system.

(3) To improve the security and stability level of the grid. The challenges of grid in Security and stability are as follows: it is more difficult to control the security and stability of large grid because of the expansion of the accident influence scope, the enhancement of requires to prevent blackouts of more demanding security; distribution network foundation is weak, and the supply reliability is lower than $99.99 \%$, there is a big gap with $99.999 \%$ of foreign countries; worldwide extreme weather events happen frequently. And frozen, intense storms, earthquakes and other natural disasters and external damage are rising; all these will give a serious threat to the security of grid. Correspondingly, the challenges of grid technologies are as follows: to master the rules of large complex grid comprehensively, to establish a sound security defense system, to develop advanced intelligent scheduling and control techniques for grid; to improve the reliable level of distribution network operation; to improve the capability of dealing with disasters of the grid.

(4) To accelerate the upgrade of the grid operation efficiency. It is urgent to solve the following three problems: the utility level of multi-type power supply technology aiming at saving and economic operation is not high; the wastage of distribution network is still can be reduced; the efficiency of unit transmission line corridor is still can be improved. Correspondingly, the challenges of grid technologies are as follows: it is necessary to study the scheduling and energy saving technology to optimize decision-making and transactions; to study the control technology of the economic operation of the distribution network, so as to further reduce the distribution network losses; to improve the design level of power transmission project, so as to improve the efficiency of unit transmission line corridor.

(5) To make the grid interact more friendly with user. We forecast, by 2020: Solar will reach 20 million kilowatts and the distributed access will reach 1.5 million kilowatts; electric vehicles will reach 17 million. The large-scale application of electric vehicles requires studying distribution technology, to studying energy storage devices to achieve flexible access. The development of intelligent buildings, intelligent community, and large-scale development of smart home equipment, requires developing advanced smart power supply technology, to establishing smart power platform, so as to guide a reasonable energy consumption way for users. The new mode of Plug and Play, flexible user interaction in energy consumption, has put forward new requests for the protection control technology and measurement technology.

\section{The Practice on SCIENCE AND Technology INNOVATION CAPABILITY BUILDING IN SGCC}

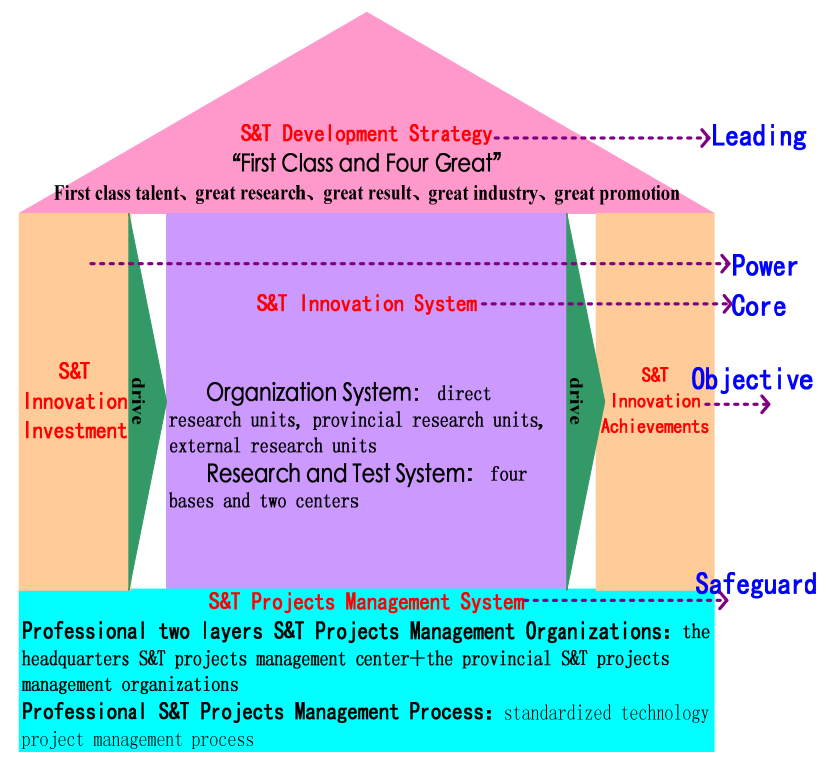

Fig. 5 The Science and Technological Innovation Capability Building System of SGCC

Facing energy technology revolution and the situation \& challenges of China's energy, SGCC strengthen science and technology innovation capability building actively to adapt to the energy challenges in the development process. SGCC has 
build a science and technology innovation capability system which is consist of "first class and four great" science and technology development strategy, technology innovation system as the core with technology project management system as the safeguard, technological innovation investment as the driving force, and the effectiveness of science and technological innovation as the goal of technological innovation capacity building, as shown in Figure 5.

In the "Eleventh Five-Year Plan" period, SGCC has used the state's preferential policies on supporting enterprises in science and technological innovation fully, has increased investment in $\mathrm{R} \& \mathrm{D}$, and the research and development cost reached a total of 24.9 billion Yuan, and the average annual growth was $24.6 \%$. SGCC has established a S\&T innovation system which focusing on science and technology team building, research resources integration, experiment and test capability improvement, application of scientific and technological achievements, intellectual property management gradually. In the S\&T innovation system, the direct research units are taken as the backbone, the provincial companies as the basis, and the external research resources as collaborative system. SGCC continues to improve research and test system, and has formed the world's most advanced power transmission and distribution research and test system, has built a "four-base and two-center" (UHV AC test base, UHV DC test base, high-altitude test base, tower test base, a large grid simulation test and measurement center) as the core of research and test system, and has formed high voltage, large power experimental research system which is the world's most complete, the test capability is the strongest, the technology level is the highest in the world, and the overall performance indicators have reached world leading level. SGCC has constructed a sound technology project management system which concludes decision-making layer, management layer, operation layer, implementation layer. It uses the hierarchical classification strategy in science and technology project management, and promotes research projects intensive and standardized management.

The science and technology innovation system of SGCC has achieved remarkable progress, and the S\&T innovation results are fruitful. Through the efforts, SGCC was named as the first "National Innovative Enterprise", and won the "Special scientific and technological innovation" award.

\section{Conclusions}

The world is undergoing a profound change in energy technology and the era of power-centered energy consumption is coming. The status of China's energy resources determines that China must develop modern power grid to meet the energy technology revolution vigorously. SGCC has explored a scientific way of science and technology innovation capability building which is fit for the characteristics of SGCC, and will optimize and improve the science and technology innovation system according to the development of the practice, and also will integrate and optimize the research resources so as to promote the science and technology innovation system and achieve synergy effect continuously. The science and technology innovation capability building practice of SGCC may have some reference to large central enterprises in China. We hope that more companies will build up a sound science and technology innovation system, so as to enhance the innovation capability of China's enterprises, to enhance our ability to respond to changes in energy, and ultimately enhance the national innovation capability.

\section{REFERENCES}

[1] SGCC. The "Twelfth Five-Year" Development plan of State Grid Corporation of China, 2010.

[2] SGCC. The "Twelfth Five-Year" Development plan of Science and Technology of State Grid Corporation of China, 2010.

[3] SGCC. The Science and Technology Management Rules Compilation of State Grid Corporation of China, 2007.

[4] National Science and Technology Department of P.R.China. National Key Basic Research Program of management practices, 2006.

[5] National Science and Technology Department of P.R.China. National Science and Technology Support Program Interim Measures.2006.

[6] National Science and Technology Department of P.R.China. National High Technology Research and Development Program (863 Program) management, 2006.

[7] National Science and Technology Department of P.R.China. Science and Technology Evaluation (tentative), 2003.

[8] LIU Bo, JIN Tianguo. R\&D project process management and information control. Harbin Institute of Technology Press, 2007.

[9] CHEN Jin. R\&D project management [M]. Mechanical Industry Press.2009. 